\title{
VARIAÇÃO PRONOMINAL EM CARTAS PESSOAIS DA FAMÍLIA PENNA
}

\author{
Rachel de Oliveira Pereira*
}

Resumo: Estudo da variação da forma pronominal $t u$ em oposição à forma você, na posição de sujeito, em cartas da família mineira de Affonso Penna, escritas em fins do século XIX e início do século $\mathrm{XX}$. Leva-se em conta na análise a dicotomia poder e solidariedade (BROWN \& GILMAN, 1960) e os pressupostos teóricos da teoria variacionista quantitativa laboviana (LABOV, 1994). Os resultados apontam para a maior utilização de você em cartas escritas por mulheres e um uso motivado da nova forma por homens.

Palavras-chave: Pronomes; cortesia; variação pronominal; cartas pessoais.

Abstract: Study of variation of the pronoun $t u$ opposed to $v o c \hat{e}$, in the subject position, in letters of Minas Gerais family of Affonso Penna, written in the late nineteenth and early twentieth century. It takes into account in the analysis the dichotomy power and solidarity (BROWN \& GILMAN, 1960) and the theoretical assumptions of the Labovian quantitative variationist theory (LABOV, 1994). The results point to greater use of você in the letters written by women and to a motivated use of the new form by men.

Keywords: Pronouns; courtesy; pronoun change; personal letters.

\section{Apresentação}

O presente estudo objetiva analisar a implementação da forma você no sistema pronominal do português do Brasil, através da descrição das formas tratamentais de segunda pessoa do singular encontradas em cartas pessoais escritas por uma família ilustre de Minas Gerais, em fins do século XIX e início do século XX.

* Universidade Federal do Rio de Janeiro. 
Estudos de sincronias passadas realizados com base em materiais diversificados vêm demonstrando que, a partir do século $\mathrm{XIX}$, o inovador você transitava por espaços discursivo-pragmáticos distintos e típicos de formas híbridas em processo de mudança. Tal forma assumia traços cerimoniosos na produção escrita da elite brasileira oitocentista (SOTO, 2007), ao mesmo tempo em que circulava como forma variante do pronome $t u$ íntimo nas relações solidárias (MACHADO, 2011).

Tendo em vista as diferentes facetas da forma inovadora $v o c \hat{e}$ na virada do século XIX para XX, o objetivo principal do estudo é analisar a variação entre $t u$ e você na posição de sujeito, como estratégias de referência ao interlocutor. Essas estratégias não serão analisadas apenas em termos descritivos, mas também à luz das teorias que discutem a questão da variação e mudança (WEINREICH, LABOV \& HERZOG, 1968) e os fenômenos da cortesia (BROWN \& GILMAN, 1960; BROWN \& LEVINSON, 1987; VIDAL, 2002).

O corpus que serve de base para a análise é escrito por uma família ilustre, constituída basicamente de políticos, por isso propõe-se observar se os papéis sociais assumidos pelos remetentes podem influenciar na escolha de uma forma em detrimento de outra. A análise não será apenas quantitativa, mas será proposta uma leitura qualitativa e pormenorizada das ocorrências encontradas nas amostras.

Baseando-se nos trabalhos de Lopes \& Machado (2005) e Rumeu (2008), busca-se verificar se a forma você é mais recorrente em cartas femininas. Além disso, pretende-se observar se o fato de as cartas em análise serem escritas por homens públicos influenciaria no tratamento empregado por eles, dependendo do papel social que eles assumem ao escrever para seus interlocutores (pai/tio/irmão/cunhado versus homem de negócio/político). 


\section{Pressupostos teóricos e metodológicos: princípios sociopragmáticos}

Nesta investigação, propõe-se estudar a relação entre os papéis sociais e as formas de tratamento empregadas nas missivas. O objetivo maior é mostrar a habilidade dos missivistas em relacionar o status e a sua representação linguística e não apenas documentar os tratamentos empregados nas cartas da família Penna. Para a realização desta análise, foram consideradas apenas as realizações correspondentes ao sujeito, que tanto poderia ser realizado plenamente ( $t u$ falas/você fala) ou como sujeito nulo expresso pela desinência verbal ( $\varnothing$ falas $/ \varnothing$ fala) .

Segundo Vidal (2002, p. 13), a pragmática é uma disciplina que leva em consideração os fatores extralinguísticos que determinam o uso da linguagem, mais precisamente, todos os fatores aos quais não se pode fazer referência em um estudo puramente gramatical, como é o caso das noções de emissor, destinatário, intenção comunicativa, contexto verbal, situação ou conhecimento de mundo.

Preti (2000) correlaciona o conceito sociológico de papel e o conceito de status que, para o autor, referem-se à participação do homem na sociedade, em seu grupo social. O status pode ser definido como as diferentes posições assumidas por um indivíduo no grupo social, que tanto pode ser primário, ou seja, restrito à família, por exemplo, ou secundário, um grupo maior, como o Estado. Um mesmo indivíduo pertence a diferentes grupos sociais, portanto, ocupando diferentes posições sociais.

Em seu estudo, Preti (2000) também afirma que, dependendo do status que o indivíduo ocupa, ele acaba ficando subordinado a certos comportamentos, que não se restringem apenas à sua postura ética, mas também a linguagem empregada por essa pessoa, já que é algo imprescindível à criação da imagem. Para o autor, as normas relacionadas ao status denominam-se papel social. Assim, pode-se afirmar com propriedade que o papel social indica o "caráter funcional do homem na sociedade" (PRETI, 2000, p. 86). 
A variação linguística seria um traço fundamental que poderia caracterizar o status do falante ao exercer seu papel social. Nesse sentido, destaca-se, especificamente, o estudo das formas de tratamento, isto é, a maneira pela qual os interlocutores se tratam mutuamente e o que a escolha de uma forma em detrimento de outras disponíveis no repertório linguístico pode significar na interação verbal.

Com o intuito de se efetuar um estudo sobre as estratégias de referência à segunda pessoa do discurso, faz-se necessária um averiguação cuidadosa das relações estabelecidas entre os participantes da situação comunicativa em questão. Para se entender essas relações, propõe-se a conjugação de algumas teorias de base pragmática, como a dicotomia poder e solidariedade, de Brown \& Gilman (1960), e a teoria da polidez, de Brown \& Levinson (1987), aliando-as aos preceitos da sociolinguística variacionista (WEINREICH, LABOV \& HERZOG, 1968).

Do estudo de Brown \& Gilman (1960), discute-se que a escolha das estratégias tratamentais referentes à segunda pessoa do discurso está regulamentada por duas relações, denominadas poder e solidariedade, que estão presentes em todas as formas de interação entre interlocutores.

O poder seria o domínio que uma pessoa exerce sobre outra em determinada situação comunicativa. Assim, para que o poder se estabeleça numa interação social, é necessário que haja pelo menos duas pessoas interagindo e que a relação estabelecida entre elas não seja simétrica. Conclui-se, então, que o poder se encontra presente nas relações assimétricas, em que o conceito de hierarquia se faz extremamente importante. Por outro lado, a solidariedade pressupõe um mesmo nível hierárquico decorrente de relações sociais simétricas. Tais relações estão ligadas, geralmente, às ideias de afinidade e afeto.

Da teoria da polidez, idealizada por Brown \& Levinson (1987), leva-se em conta que na interação verbal os participantes possuem duas propriedades básicas que podem explicar seu 
comportamento: a racionalidade e a imagem pública. No primeiro caso, considera-se que cada indivíduo tem um modo de raciocinar que pode ser definido de modo preciso e que o conduz aos meios necessários para chegar aos fins que deseja alcançar. No caso da segunda propriedade, defende-se que cada indivíduo constrói uma imagem para si próprio, buscando manter o prestígio no meio social em que vive. A imagem pública possui duas vertentes: a face positiva e a negativa. A primeira consiste na personalidade (imagem) desejada pelos interactantes, ou seja, a maneira como os indivíduos desejam ser vistos pela sociedade. A face negativa, por outro lado, está relacionada ao território, ao direito de sofrer perturbação, à preservação pessoal, o que remete à liberdade de ação e à liberdade para não sofrer imposição por parte dos outros.

Segundo os autores, qualquer ato de fala em si é considerado um ato de ameaça à face de nosso interlocutor, porque a imagem pública é vulnerável e a interação verbal nada mais é do que um esforço para preservá-la. Desta forma, as estratégias de polidez ou cortesia são empregadas para reforçar a imagem positiva do emissor e/ou do interlocutor, isto é, garantir a harmonia do processo interativo. Quando há uma estratégia que suaviza a imposição de um ato que ameace a face positiva do interlocutor, tem-se um caso de polidez positiva, e quando esse ato ameaça a face negativa, a estratégia utilizada é a polidez negativa.

Aliado ao estudo sociopragmático, estão os pressupostos sociolinguísticos, em que se procura (i) pesquisar o grau de estabilidade ou mutabilidade do fenômeno variável, (ii) observar quais são as circunstâncias que favorecem ou não os usos alternativos e (iii) antever o comportamento sistemático e regular da variação. Para isso, é necessário, na análise linguística, considerar a inter-relação entre os fatores internos e externos ao sistema. 


\section{O corpus}

A amostra utilizada neste estudo é composta por $87^{1}$ cartas pertencentes à família Penna: uma importante família de políticos de Minas Gerais. Grande parte de seus membros se estabeleceu em cidades interioranas mineiras, como Santa Bárbara, Sabará e Barão de Cocais, na parte oeste do estado, cidades estas pertencentes ao chamado Circuito do Ouro de Minas Gerais. Embora os seus integrantes tenham começado sua carreira política nessas cidades, após conseguirem certo status em suas carreiras, muitos deles acabaram migrando para outras cidades maiores e mais desenvolvidas, como Belo Horizonte e Rio de Janeiro.

Para a realização desse estudo obteve-se um conjunto de missivas destinadas a um único destinatário, Affonso Penna Júnior, o que nos permitiu verificar as alterações do tratamento em função da relação estabelecida entre cada um dos remetentes: o expresidente da República, Affonso Penna; o irmão mais novo, Alvaro Penna; sua mãe, Maria Guilhermina Penna; seu tio, Manuel Penna; e seu cunhado, Edmundo Veiga.

No entanto, há algumas idiossincrasias que diferenciam as missivas entre si. Como se sabe, a família era formada basicamente por políticos, o que fazia com que as cartas escritas por homens tratassem direta ou indiretamente desse assunto, enquanto que as cartas femininas se referiam a aspectos relacionados à rotina da família. $\mathrm{O}$ quadro a seguir especifica a distribuição das missivas familiares com dados sobre o grau de parentesco, o período de escritura, a idade do remetente e do destinatário das cartas:

\footnotetext{
${ }^{1}$ Grande parte do material selecionado para compor esta amostra foi coletada no Arquivo Nacional do Rio de Janeiro. Uma pequena parte foi cedida gentilmente por Affonso Augusto Moreira Penna, bisneto de Affonso Penna e neto de Affonso Penna Júnior.
} 
TABELA 1

Distribuição do corpus

\begin{tabular}{|c|c|c|c|c|c|c|}
\hline Remetente & Destinatário & Parentesco & $\begin{array}{c}\text { Número } \\
\text { de cartas }\end{array}$ & Período & $\begin{array}{c}\text { Idade do } \\
\text { remetente }\end{array}$ & $\begin{array}{c}\text { Idade do } \\
\text { destinatário }\end{array}$ \\
\hline Affonso Penna & \multirow{5}{*}{$\begin{array}{l}\text { Affonso } \\
\text { Penna } \\
\text { Júnior }\end{array}$} & Pai & 19 & $1897-1907$ & $50-57$ & $18-28$ \\
\hline Álvaro Penna & & Irmão & 12 & $1902-1908$ & $21-27$ & $23-29$ \\
\hline Edmundo Veiga & & Cunhado & 16 & 1909-1922 & $40-53$ & $30-43$ \\
\hline Manuel Penna & & Tio & 10 & 1906-1909 & $60-63$ & $27-29$ \\
\hline $\begin{array}{l}\text { Maria } \\
\text { Guilhermina } \\
\text { Penna } \\
\end{array}$ & & Mãe & 30 & $1896-1927$ & $39-70$ & $17-48$ \\
\hline
\end{tabular}

4. A distribuição do sujeito nas cartas da família Penna

Serão observadas as ocorrências de sujeito nas cartas da família Penna. O parentesco existente entre remetente e destinatário das cartas foi selecionado pelo programa Goldvarb $X$ como relevante para a análise. Posto que os resultados de outros trabalhos atestem que o pronome $t u$ era utilizado em contextos de maior intimidade e familiaridade no século XIX/XX (LOPES \& MACHADO, 2005), postula-se que, quanto mais íntima e próxima a relação de parentesco, maior a probabilidade de o informante utilizar o pronome $t u$.

Nesta amostra, poderiam ser estabelecidas cinco relações diferentes entre os interlocutores: mãe/filho, pai/filho, tio/sobrinho, irmão/irmão e cunhado/cunhado. Cabe destacar que, a princípio, todas as relações identificadas nas cartas familiares foram consideradas íntimas, ficando a cargo dos assuntos abordados na missiva para confirmar se as relações estabelecidas eram solidárias e próximas. A tabela a seguir apresenta os resultados encontrados: 


\section{TABELA 2}

A influência do grupo parentesco na variação entre $t u$ e você na posição de sujeito (valor de aplicação tu)

\begin{tabular}{lccc}
\hline Fatores & Aplicação/Total & $\%$ & PR \\
\hline Irmão & $25 / 29$ & $86 \%$ & 0.93 \\
Tio & $30 / 38$ & $79 \%$ & 0.89 \\
Cunhado & $22 / 50$ & $44 \%$ & 0.42 \\
Pai & $31 / 64$ & $48 \%$ & 0.33 \\
Mãe & $44 / 110$ & $40 \%$ & 0.26 \\
\hline
\end{tabular}

A tabela aponta em termos de peso relativo, um favorecimento no emprego de $t u$ sujeito por dois informantes: Manuel Penna (PR 0.89) e Alvaro Penna (PR 0.93), tio e irmão de Affonso Penna Júnior, respectivamente. Por outro lado, três missivistas utilizam preferencialmente a forma você na posição de sujeito: Edmundo Veiga (PR 0.42), Affonso Penna (PR 0.33) e Maria Guilhermina Penna (PR 0.26), respectivamente, cunhado, pai e mãe do destinatário.

Visto que os missivistas Manuel e Alvaro utilizam majoritariamente $\boldsymbol{t} u$ sujeito e, em conjunto, apresentam apenas 12 dados de você, é interessante verificar quando esta forma aparece em suas cartas. Alguns exemplos podem ser observados a seguir:

(01) “(...) não tenhas man | dado o que me disseste doaria a Camara | para ser collocada no lugar de honra seria | bom que no dia 7 , voce vissi e não podendo | talvez o Amarilio com algum companheiro | que [pudessi] discursar e fazer propaganda eu | mandaria a condução." (Carta de Manuel Penna a Affonso Penna Júnior, em 24/ 08/1909, negrito nosso)

O exemplo (01) mostra um emprego motivado da forma você, já que, nesse caso, aparentemente há uma ordem dissimulada em um pedido o que favorece o emprego de um tratamento mais atenuante.

Uma vez que na posição de sujeito o missivista utiliza predominantemente $t u$ nulo, conclui-se que o você não é, nas suas cartas, uma variante pronominal, mas uma forma de tratamento que 
minimiza uma solicitação feita pelo remetente. Ressalte-se também o fato de Manuel Penna utilizar $t u$ nulo antes ou depois do pedido ser feito, o que é mais um indício de que a utilização de você por ele é uma forma atenuante para uma solicitação.

Assim como Manuel, Alvaro Penna utiliza quase que categoricamente o $t u$ sujeito, com exceção de quatro dados. Ressalta-se que, dos quatro dados de você encontrados na sua produção, três são de sujeito nulo, havendo apenas um dado de você pleno. No entanto, diferentemente de Manuel Penna, não se observa nas cartas de Alvaro a utilização da nova forma para atenuar pedidos. Apesar disso, observando atentamente os contextos em que estas formas aparecem, viu-se que a nova forma é utilizada quando o missivista trata de assuntos políticos e nunca familiares, como fica notável no exemplo a seguir:

(02) "Você quer vêr phantasia nas minhas | cismas de politicagem, mas, a tua | bôa fé nem do desconhecimento des- | sas coisas de raça, desde que cheguei | soffro um assedio incessante." (Carta de Alvaro Penna a Affonso Penna Júnior, em 08/11/1905, negrito nosso)

Acredita-se que a temática presente nas missivas seja um fator determinante para a escolha das formas tratamentais. Aparentemente, um trecho em que o assunto abordado seja a política apresenta um tema que requer mais cuidado ao ser comentado por se tratar de um assunto mais delicado ou até sigiloso. Solicitações na esfera política certamente ameaçam a imagem pública de quem pede e de quem deveria atender ao pedido. Comentários sobre como tem passado a família ou a busca de notícias do destinatário seriam bem menos ameaçadores à face do outro. Dessa forma, ao se tratar de um assunto que exige mais cautela, o missivista opta por um tratamento mais respeitoso e menos direto para expressar suas opinióes políticas. Mais uma vez se observa um uso motivado de você.

Serão observados agora os resultados encontrados nas missivas de Edmundo Veiga, Affonso Penna e Maria Guilhermina Penna, favorecedores da nova forma. 


\subsection{O favorecimento de você: Edmundo Veiga, Affonso Penna e Maria Guilhermina Penna}

Enquanto Alvaro e Manuel Penna apresentaram uso majoritário de $t u$, Affonso Penna e Edmundo Veiga (pai e cunhado de Affonso Penna Júnior, respectivamente) ilustram índices percentuais equilibrados no que se refere à variação do sujeito. Em sua produção escrita, Edmundo apresenta 56\% ocorrências de sujeito relacionadas à forma você, ao passo que Affonso Penna possui frequências ainda mais acirradas: $52 \%$ de dados de você e $44 \%$ de $t u$. O peso relativo indica uma menor probabilidade do emprego do pronome $t u$ entre esses dois missivistas: 0.42 para Edmundo e 0.33 para Affonso.

Por oposição, essas frequências e pesos relativos desfavoráveis a $t u$ indicam que os dois missivistas empregam mais você. Como a variação é polarizada na produção escrita desses missivistas, a análise dos contextos de ocorrência pode elucidar a forte presença de algum tipo de motivação discursivo-pragmática para o emprego da forma você. Defende-se aqui que o emprego de $t u$ e você na posição de sujeito ainda não constitui, em cartas de alguns dos missivistas, formas legitimamente variantes na acepção da teoria variacionista laboviana. Isso se justifica pelo predomínio quase categórico da forma desinencial verbal na segunda pessoa do singular (sujeito tu nulo) e o eventual emprego de você como sujeito pleno em determinados contextos específicos, principalmente, em atos linguísticos ameaçadores à face do remetente (BROWN \& LEVINSON, 1987): pedidos de cargos ou favores que causem algum tipo de constrangimento para ambas as partes. É nesse sentido que se afirma aqui que você e $t u$ na posição de sujeito ainda não são, na correspondência de alguns membros da família Penna, formas pronominais variantes:

(03) "Pelo teo telegramma e cartão soubemos que | fizeste boa viagem, o que veio tranquilizar- | nos, pois teo estado de saude não parecia bom | quando partiste. || Deos permitta que tenhas | passado bem e que o mesmo aconteça | aos nossos parentes." (Carta de Affonso Penna a Affonso Penna Júnior, em 21/01/1902, negrito nosso) 
(04) "O Neca pode | bem encarregar se de arranjar isso. | Avise me com antecedencia o dia que | Você marcar para sahida de B. $\mathrm{H}^{\text {te }}$ Você deve | convidar o Neca para vir consigo, refor- | çando a carta que vou escrever lhe nesse | sentido." (Carta de Affonso Penna a Affonso Penna Júnior, em 20/04/1907, negrito nosso)

(05) “Tens passado muito tempo sem | vir ao Rio, o que (a vinda) tem | certa utilidade, para assumpar | e mostrar actividade de negocios. I Sabes que em nossa casa tua pre- | sença e dos nossos é sempre mo- | tivo do maior contetamento." (Carta de Edmundo Veiga a Affonso Penna Júnior, em 27/09/1911, negrito nosso)

(06) "Irmão amigo, || Estão feitas as transferencias das | acções da Mercantil para seu nome, | podendo Você fazer a entrada do dinhei- | ro ahi (refiro-me á $5^{a}$ chamada), pe- | dindo ao José Pedro que comuni- | que ao Banco o pagamento feito." (Carta de Edmundo Veiga a Affonso Penna Júnior, em 19/05/1911, negrito nosso)

A partir da análise desses exemplos, nota-se que o pronome tu é utilizado pelos missivistas para dirigir-se ao interlocutor tratando de assuntos mais familiares e íntimos, enquanto a forma você aparece quando o remetente dá uma ordem (no caso do pai) e para conversar sobre negócios (no caso do cunhado).

Nesses casos, a forma você ainda não se caracteriza como uma variante pronominal de segunda pessoa do singular, mas como uma forma atenuadora de um assunto mais delicado e não tão próximo, ou para atenuar ordens e pedidos, como já foi visto ao esmiuçar o tratamento utilizado por Alvaro e Manuel Penna.

Nos dados de você produzidos pelos representantes masculinos da família Penna, observou-se um uso motivado da nova forma, escolhido para suavizar solicitações feitas ou no momento em que os missivistas abordam assuntos que necessitam de mais cautela. Assim, ao utilizar uma forma tratamental mais respeitosa, os remetentes preservam a face do receptor da mensagem (BROWN \& 
LEVINSON, 1987). A única missivista que apresenta um uso de você diferenciado do que foi visto até então é Maria Guilhermina Penna, de quem será tratado agora.

\subsection{O comportamento linguístico de Maria Guilhermina Penna}

A única missivista que possui comportamento linguístico distinto dos homens da família Penna é Maria Guilhermina, que emprega mais você sujeito em $60 \%$ de sua produção escrita. Este fato corrobora outros estudos de natureza diacrônica com base em cartas de fins do século XIX e início do século XX (SOTO, 2001; LOPES \& MACHADO, 2005; RUMEU, 2008), vêm demonstrando um emprego mais sistemático e produtivo da forma gramaticalizada/ pronominalizada você pelas mulheres.

Ressalta-se que tal emprego mais frequente nas cartas da mãe de Affonso Penna Júnior, não parece estar relacionado a uma assimetria de tratamento - de mãe/superior para filho/inferior-como já foi encontrado em outros corpora (SOTO, 2001; RUMEU, 2008). Nessas cartas em específico, percebe-se que as correspondências remetidas possuem um tom altamente afetuoso: as missivas geralmente relatam a rotina da família, as saudades que esta mãe zelosa sente do filho Affonsinho e dos amados netos, sempre em busca de notícias. Portanto, trata-se de "um uso mais generalizado do que um pronome de poder ou solidariedade" (SOTO, 2001, p. 186), uma vez que a forma inovadora você cada vez mais avança nos espaços funcionais típicos de $t u$. Inclusive, a variação entre você e $t u$, presente em uma mesma missiva, ocorre com maior frequência nas cartas escritas por ela, como se observa no exemplo a seguir:

(07) "Querido Filho || Recebi os jornaes que vocé me man| dou, appreciei muito os discursos e | a imponente posse que tiveste." (Carta de Maria Guilhermina Penna a Affonso Penna Júnior em 11/08/1919, negrito nosso)

O fato de Maria Guilhermina empregar com maior frequência você sujeito em suas missivas confirma o maior emprego da forma 
inovadora por figuras femininas. O que se tem observado no período, através de análises com amostras diversificadas, é um uso de $t u$ como forma de intimidade e nas relações simétricas e solidárias entre homens. As mulheres costumam utilizar mais você, talvez pelo fato dessa estratégia ainda preservar algum distanciamento social, como também afirmam Lopes \& Cavalcante (2011).

O comportamento linguístico de Maria Guilhermina corrobora o estudo de Rumeu (2008), no qual se afirma que as mulheres seriam as propulsoras da inserção de você no quadro de pronomes do português brasileiro. De acordo com o estudo da pesquisadora, analisando a variação entre $t u$ e você em cartas pessoais do século XIX, a inserção da forma inovadora como pronome pessoal teria sido impulsionado pelas figuras femininas, já que são as mulheres que mais utilizam a nova forma.

Pelo fato da missivista ter escrito ao filho num intervalo de quase 30 anos, foi possível tentar observar se a missivista apresenta uma atitude linguística que se mantém estável ou instável em relação ao emprego de $t u$ e você, no intervalo temporal no qual ela escreve ao filho.

Entende-se como atitude estável a não alteração do comportamento linguístico da missivista e, por atitude instável, a mudança no desempenho linguístico nesse lapso temporal que recobre a vida da informante - metade da vida adulta ( 40 a 60 anos) e início da velhice - conforme prevê Labov (1994), em sua busca por depreender a estabilidade dos indivíduos no decorrer do tempo.

Desta maneira, espera-se confirmar a maior propensão de Maria Guilhermina em utilizar a nova forma, com base nos estudos de Lopes \& Machado (2005) e Rumeu (2008). Para realizar este estudo, foram analisadas 15 cartas da informante, ${ }^{2}$ escritas por ela na metade de sua idade adulta ( 40 a 60 anos) e início da velhice (60 a 70 anos), entre os anos de 1898 a 1926, conforme é possível conferir na tabela abaixo:

\footnotetext{
${ }^{2}$ Ressalta-se que foram excluídas da análise cinco cartas que não possuíam data e quinze que não apresentavam dados de sujeito.
} 
TABELA 3

A variação tratamental no comportamento linguístico de Maria Guilhermina ao longo de quase 30 anos em que escreve ao filho

\begin{tabular}{|c|c|c|c|c|}
\hline \multirow[t]{2}{*}{ Ano } & \multirow{2}{*}{$\begin{array}{l}\text { Idade da } \\
\text { remetente }\end{array}$} & \multirow{2}{*}{$\begin{array}{c}\text { Idade do } \\
\text { destinatário }\end{array}$} & \multicolumn{2}{|c|}{ Sujeitos } \\
\hline & & & $T u$ & Você \\
\hline 1898 & 41 & 19 & $\begin{array}{c}3 / 3 \\
100 \% \\
\end{array}$ & - \\
\hline 1899 & 42 & 20 & $\begin{array}{c}2 / 2 \\
100 \%\end{array}$ & 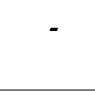 \\
\hline 1904 & 47 & 25 & $\begin{array}{l}5 / 20 \\
25 \%\end{array}$ & $\begin{array}{c}15 / 20 \\
75 \%\end{array}$ \\
\hline 1906 & 49 & 27 & $\begin{array}{c}2 / 3 \\
67 \% \\
\end{array}$ & $\begin{array}{c}1 / 3 \\
33 \% \\
\end{array}$ \\
\hline 1907 & 50 & 28 & $\begin{array}{c}5 / 5 \\
100 \% \\
\end{array}$ & - \\
\hline 1908 & 51 & 29 & $\begin{array}{l}9 / 20 \\
45 \% \\
\end{array}$ & $\begin{array}{c}11 / 20 \\
55 \% \\
\end{array}$ \\
\hline 1909 & 52 & 30 & - & $\begin{array}{c}4 / 4 \\
100 \%\end{array}$ \\
\hline 1910 & 53 & 31 & - & $\begin{array}{c}2 / 2 \\
100 \% \\
\end{array}$ \\
\hline 1919 & 62 & 40 & $\begin{array}{l}1 / 9 \\
2 \%\end{array}$ & $\begin{array}{c}8 / 9 \\
98 \% \\
\end{array}$ \\
\hline 1920 & 63 & 41 & $\begin{array}{l}3 / 12 \\
11 \%\end{array}$ & $\begin{array}{l}9 / 12 \\
89 \%\end{array}$ \\
\hline 1926 & 69 & 47 & - & $\begin{array}{c}3 / 3 \\
100 \% \\
\end{array}$ \\
\hline Total & & & $\begin{array}{c}30 / 74 \\
40 \%\end{array}$ & $\begin{array}{c}44 / 74 \\
60 \%\end{array}$ \\
\hline
\end{tabular}

A análise do desempenho linguístico de Maria Guilhermina evidenciou que ela emprega categoricamente $t u$ sujeito entre os anos de 1898 até 1907, como se observa nos exemplos (08) e (09): 
(08) "Chim, meu querido Filho | Gosto muito de receber tuas | cartinhas, vejo n'ellas o amor | que me tens, e a teus Irmãos. | Fiquei muito contente de ver | a defeza que fazes do Alvaro. | Deos os conserve sempre uni- | dos, e amigos." (Carta de Maria Guilhermina Penna a Affonso Penna Júnior em 23/09/1898, negrito nosso)

(09) “Querido Filho | D'esde que Marieta chegou | estou querendo te escrever mas | não tenho tido tempo. | As saudades dobrarão com a | vinda della e dos meus ne- | tinhos, fiquei pesarosa de | não teres vindo, faço ideia | da falta que deves estar | sentindo delles e isto me | faz pensar mais em ti | e ter mais saudades. Bem | sei que não viestes porque | és cumpridor | de teus deve- | res e trabalhador como teu | Pai, e isto me orgulha | mas... as mãis gostão mais | de consultarem o coração e | eu desejaria que estivesses aqui | commigo." (Carta de Maria Guilhermina Penna a Affonso Penna Júnior em 14/05/1907, negrito nosso)

Diferentemente desses resultados, o ano de 1904 mostrou-se completamente díspar do que a missivista havia produzido neste período. Nesse ano, as ocorrências de $t u$ sujeito caem drasticamente, ao passo em que a produção de você aumenta, chegando a $75 \%$ de frequência. O exemplo a seguir ilustra dados de sujeito do ano em questão:

(10) "Querido Filho | Tenho appreciado as boas noticias | que me dão de vocé estar mais | alegre, mais animado e com me- | lhor saude. Tenho esperança que | você fique bom das enxaquecas, | estando agora mais calmo. | É precizo que você participe o | seu casamento ao parentes e | amigos. (...) Estou admirada | de vocé fallar em levar o Er- | nesto a $S^{\text {ta }}$ Barbara, agora que | devias estar contente de não ter | viagem nenhuma para fazer e | poder estar ao lado da Marieta." (Carta de Maria Guilhermina Penna a Affonso Penna Júnior em 15/09/1904, negrito nosso) 
A maior utilização de você nessa carta talvez possa ser explicada pelo teor da mesma. Diferentemente das outras cartas vistas até então, em que Maria Guilhermina saúda ou relata seus sentimentos e desejos ao filho, essa carta caracteriza-se praticamente pela presença de conselhos e perguntas. Por esse motivo, a missivista utiliza um tratamento que atenua suas solicitações.

De acordo com Vidal (2002), ações como perguntar, pedir e sugerir necessitam de recursos específicos para garantir um tom de polidez adequado porque se caracterizam como uma "descortesia intrínseca" (VIDAL, 2002, p. 145) que devem ser compensadas por meio de outras fórmulas de cortesia relativa que a mitiguem. Assim, a forma você teria uma função atenuante, pois, pelo fato da carta possuir um teor mais delicado, há chances dos conselhos e pedidos de Maria Guilhermina serem ações que entrem em conflito com os desejos e interesses do filho.

A partir do ano de 1908, contata-se que a frequência de $t u$ diminui gradativamente, tendo $45 \%$ de frequência em 1908, $2 \%$ em 1919 e 11\% em 1920, ao passo que as utilizações de você vão aumentando, como se pode conferir nos trechos retirados de algumas cartas da missivista, abaixo:

(11) "Talvez você | lhe preste bom serviço | ficando ahi mais tem- | po para ver o que ha a | respeito, escrever lhe sem- | pre dando noticias emfim | com o seu tino e amabilida- | de podes perceber o que | há é preciso cuidado que | sabem iludir a gente; as- | sim prestarás bom serviço | a Papai que muito precisa | e que nos quer tanto bem. | Vocé ahi é pessoa amiga | dedicada de toda confian- | ça de Papai e isso nos va- | le muito e muito agora." (Carta de Maria Guilhermina Penna a Affonso Penna Júnior em 16/11/1908, negrito nosso)

(12) "Sinto bem você não ter mais | calma para fazer o seu tra | balho, não se alimentar bem | e com socego. Agora você deve | estar mais tranquillo e | mais contente com a pre- | sensa de Marieta e filhi- | nhos." (Carta de Maria Guilhermina Penna a Affonso Penna Júnior em 23/09/1919, negrito nosso) 
Os exemplos (11) e (12) ilustram o comportamento instável da missivista numa mesma carta. Nos dois exemplos, é possível identificar que a informante tanto $t u$ quanto você sujeito na mesma carta.

A Tabela 3 indica que há um uso contínuo e gradativo de você conforme a missivista aumenta de idade - saindo da idade adulta e se aproximando da velhice - ao passo que a frequência de $t u$ diminui, ao ponto de nos anos de 1909, 1910 e 1926 não haver mais ocorrências nas cartas da missivista, como se observa nos exemplos a seguir:

(13) "Vocé tem recebido 20 volu- | mes que o Mordomo mandou? | Escrevi uma carta de 4 paginas | e vocé diz que não recebeu, não gos- | tei nada d'isso." (Carta de Maria Guilhermina Penna a Affonso Penna Júnior em 01/03/1909, negrito nosso)

(14) "Achei que você foi mui- | to depressa tomar conta do serviço | devia ter esperado ficar mais forte. (...) Você tem mandado o dinheiro | d'ella? Ella não se esquece de vocês." (Carta de Maria Guilhermina Penna a Affonso Penna Júnior em 13/04/1926, negrito nosso)

Os exemplos (13), e (14) ilustram a fase final do comportamento linguístico de Maria Guilhermina: o uso categórico de você sujeito, inclusive, aparecendo como sujeito nulo, o que, segundo Rumeu (2008), indica que a nova forma estaria ocupando os mesmos espaços funcionais de $t u$.

Os resultados indicam que Maria Guilhermina possui um comportamento linguístico variável. $O$ gráfico a seguir ajuda a visualizar com mais clareza tal mudança: 


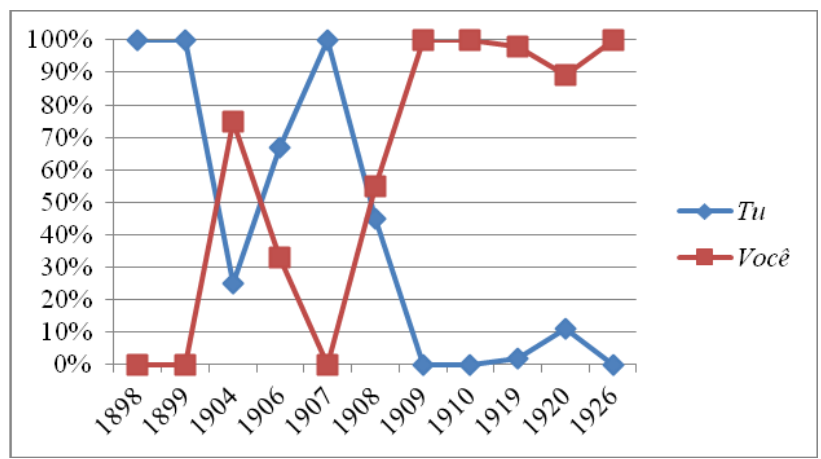

GRÁFICO 1: A variação tratamental no comportamento linguístico de Maria Guilhermina ao longo de quase 30 anos em que escreve ao filho

A partir da análise das cartas de Maria Guilhermina ainda adulta, entre os anos de 1898 a 1907 pode-se contatar o uso majoritário de $t u$ sujeito e o emprego motivado da forma você. É possível observar, a partir de 1908, o delineamento de uma curva descendente de $t u$ e uma curva ascendente de você que passa a ser utilizado paulatinamente, conforme a missivista se aproxima da velhice.

Em síntese, o que se percebe a partir desses resultados distintos entre os homens e as mulheres da família Penna quanto à variação entre $t u$ e você na posição de sujeito é, principalmente, a polifuncionalidade da forma gramaticalizada você na produção epistolar do século XIX. Como mostraram Rumeu (2008) e Lopes et al. (2009), nas missivas de fins do século XIX, o inovador você transita por espaços discursivo-pragmáticos distintos e típicos de formas híbridas em processo de mudança. Em alguns contextos e na pena de alguns missivistas, principalmente os mais ilustres políticos da família, a forma você é utilizada para amenizar ou suavizar pedidos. Nesses casos, o você ainda conservaria algumas propriedades da antiga forma de tratamento da qual adveio (vossa mercê). Por outro lado, nas cartas de Maria Guilhermina, a nova forma você comporta-se mais claramente como uma forma variante de $t u$. Isso ocorre em fins do século XIX. Na segunda década do século XX, Guilhermina emprega mais comumente a forma você e esse uso não necessariamente funciona para atenuar pedidos como antes. 


\section{Considerações finais}

A partir da breve análise de parte das correspondências particulares da família Penna, pode-se fazer algumas constatações sobre a questão da distribuição das estratégias de referência à segunda pessoa.

Primeiramente, o estudo corrobora outros trabalhos de mesmo cunho, apresentando em fins do século XIX e início do século $\mathrm{XX}$, a forma pronominal $t u$ ainda sendo mais empregada em missivas de cunho pessoal e íntimo.

A partir da análise das ocorrências de sujeito, verificou-se um comportamento distinto no emprego de você entre homens e mulher. A análise das cartas de Alvaro Penna e Manuel Penna, indica o uso do pronome $t u$ quase categoricamente, em que há apenas pouco mais de $\mathbf{1 0}$ dados da nova forma. Verificou-se um emprego motivado de você para fazer solicitações e pedidos ou tratar de política. Por outro lado, embora Edmundo Veiga e Affonso Penna tenham aparecido favorecendo a nova forma, o que se viu foi novamente a utilização motivada de você, como forma de mitigar assuntos que ameaçam à face do interlocutor, como é o caso dos dois missivistas. Assim, conclui-se que a utilização de uma forma em detrimento de outra nas cartas masculinas está intimamente ligada ao papel social que o missivista assume quando escreve suas cartas: os homens empregam $t u$ para tratar de assuntos mais íntimos e pessoais, ao passo que a forma você é utilizada quando os missivistas assumem seus papéis sociais de homens de negócios. Desta forma, confirma-se o postulado de que quanto mais íntima e próxima a relação de parentesco, maior a probabilidade de o informante utilizar o pronome $t u$.

Diferentemente dos homens, Maria Guilhermina, a única informante mulher da amostra, mostrou um comportamento linguístico instável ao longo dos quase 30 anos em que escreve ao filho: passando de uma adulta que utilizava categoricamente $t u$ a uma idosa que empregava a forma você, sem que este emprego 
seja motivado, como visto nas cartas masculinas. Por este motivo, o estudo corrobora a hipótese de que seriam as mulheres as grandes propulsoras da implementação de você no sistema pronominal do português do Brasil.

\section{Referências}

BROWN, R.; GILMAN, A. The pronouns of power and solidarity. In: SEBEOK, T.A. Style in language. Massachusetts: MIT Press, 1960. p. 253-276.

BROWN, P.; LEVINSON, S. Politeness: some universals in language usage. Cambridge: Cambridge University, 1987.

LABOV, W. Principles of linguistic change: internal factors. Oxford: Blackwell, 1994.

LOPES, C. R. dos S.; MACHADO, A. C. M. Tradição e inovação: indícios do sincretismo entre segunda e terceira pessoas nas cartas dos avos. In: LOPES, C. R. dos S. (Org.) Norma brasileira em construção: fatos lingüísticos em cartas pessoais do século XIX. Rio de Janeiro: PósGraduação em Letras Vernáculas da UFRJ/FAPERJ, 2005. p. 45-66.

LOPES, C. R. dos S.; MARCOTULIO, L.L.; SANTOS, V. M.; SILVA, A. S. Quem está do outro lado do túnel? Tu ou você na cena urbana carioca. Neue Romania, Berlin, v. 39, p. 49-66, 2009.

LOPES, C. R. dos S.; CAVALCANTE, S. A cronologia do voceamento no português brasileiro: expansão do você-sujeito e retenção do clíticote. Lingüística, Madrid, v. 25, p. 1-35, 2011.

MACHADO, A. C. M. As formas de tratamento nos teatros brasileiro e português dos séculos XIX e XX. Tese (Doutorado em Língua Portuguesa) - Universidade Federal do Rio de Janeiro, Rio de Janeiro, 2011.

PEREIRA, R. de O. O tratamento em cartas amorosas e familiares da Família Penna: um estudo diacrônico. Dissertação (Mestrado em Língua Portuguesa) - Universidade Federal do Rio de Janeiro, Rio de Janeiro, 2012. 
PRETI, D. Papéis sociais e formas de tratamento em A ilustre casa de Ramires, de Eça de Queiroz. In: BERRINI, B. (Org.). A ilustre casa de Ramires: cem anos. São Paulo: EDUC, 2000.

RUMEU, M. C. de B. A implementação do "você" no português brasileiro oitocentista e novecentista: um estudo de painel. Tese (Doutorado em Língua Portuguesa) - Universidade Federal do Rio de Janeiro, Rio de Janeiro, 2008.

SOTO, E. U. M. S. Variação/mudança do pronome de tratamento alocutivo: uma análise enunciativa em cartas brasileiras. Tese (Doutorado em Linguística e Língua Portuguesa) - Universidade Estadual Paulista "Júlio de Mesquita Filho", Araraquara, 2001.

VIDAL, M. Introducción a la pragmática. Barcelona: Ariel, 2002.

WEINREICH, U.; LABOV, W.; HERZOG, M. Fundamentos empíricos para uma teoria da mudança linguística. São Paulo: Parábola, 2006. [1. ed. ing., 1968]

Recebido para publicação em 28 de agosto de 2012 Aprovado em 13 de novembro de 2012 